\title{
Morphofunctional features of females depending on the climatic conditions of Altay republic
}

\begin{abstract}
To study the morphofunctional features of females depending on the climatic and geographical conditions of residence is available and relevant. The aim of the study: to identify morphofunctional features of the females living in the highlands of the southern Altai. We evaluated the body length, weight, and mass index; antiradical and antioxidant activity of blood plasma of women 20-59 years old depending on the climatic and geographical area of residence. We also determined the age of menopause in women 40-59 years old in the conditions of the low-mountains and middle-mountains of the Altai. It was found that the body length of women in the Altai middle-mountains was lower and the body mass index was higher than that of women in the low mountains. The period of functioning of the sexual glands in women of the middle-mountains was shorter than in women living in a favorable climate of the low-mountains. The antioxidant and anti-radical activity of blood plasma was reduced in adverse climatic conditions. Consequently, women in the population of southern Altaians living in the middle-mountains with discomfort climate conditions have adaptive signs, which are manifested in morphofunctional parameters.
\end{abstract}

Keywords: females, climate, adaptation, morphofunctional features
Volume 7 Issue 5 - 2020

\author{
Chanchaeva EA,' Gerasev AD, ${ }^{2}$ Roman \\ Aizman $^{2}$ \\ 'Physical education and sports, Physiology and Safety of Life, \\ Gorno-Altaisk State University, Russia \\ ${ }^{2}$ Human Anatomy, Physiology and Safety of Life, Novosibirsk \\ State Pedagogical University, Russia
}

Correspondence: Aizman Roman, Doctor of Biological Sciences, Professor, Honored worker of science of the Russian Federation, Head of the Department of Anatomy, Physiology and Life Safety, Novosibirsk State Pedagogical University, Russia, Tel +79I39I I9564, Fax +7383244058I

Email aizman.roman@yandex.ru

Received: August 14, 2020 | Published:September 08, 2020

\section{Introduction}

One of the main indicators of the state's well-being is the life expectancy of its population. In the Russian Federation, there is a clear geographical disparity in life expectancy: low values are registered in the republics of Tuva and Altai, and high values are registered in the republics of the North Caucasus. ${ }^{1}$ Environmental conditions have a significant impact on the manifestation of human genotypic traits. High-altitude areas of the southern Altai are characterized by unfavorable climatic conditions, which along with other factors determine the functioning of the human organism. Questions about the signs of aging and life expectancy associated with regular estrous cycles are widely discussed in the literature. ${ }^{2,3}$ The females, in contrast to the males, have a pronounced border of extinction of the functions of the sexual glands, so the study of this sign, depending on climatic conditions, is accessible and relevant.

\section{The aim of the study}

To identify morphofunctional features of the female organism in the middle lands of the southern Altai.

\section{Research problems}

a. To estimate the body length, weight and mass index, antiradical and antioxidant activity of blood plasma of women 20-59 years old, depending on the climatic and geographical area of residence;

b. To determine the age of menopause in women 40-59 years living in low-mountains and middle-mountainsAltai.

\section{Methods}

The territory of the Altai mountains is clearly divided into three zones (foothill, low-mountains and middle-mountains), which are spatially compressed and differ in the contrast of climatic and geographical conditions. Representatives of the indigenous population are the Altai-Kizhi (southern Altaians). The study was conducted in the village of Nizhnyaya Talda ( $800 \mathrm{~m}$ above sea level) and the village of Kokoria (1900m above sea level). The middle-mountain regions of the southern Altai are characterized by extremely unfavorable climatic conditions, while the low-mountain regions are characterized by a suboptimal climate. The ethnic composition of the surveyed localities (each numbering about 1000 people) was represented exclusively by southern Altaians.

We conducted a cross-sectional study of southern Altai women using a random sample based on the following criteria: length, weight, and body mass index. Anthropometric measurements were performed using the standard methodic. Body weight was measured using a medical scale, and body length was measured using a medical height meter. The body mass index (BMI, $\mathrm{kg} / \mathrm{m}^{2}$ ) was calculated. These measurements were carried out in 109 women aged 20 to 59 years, 53 of them from the middle-mountains and 56 from the low-mountains. The survey method was used to determine the time of onset of menopause by age, when there was a violation of the menstrual cycle. A total of 42 women aged $40-59$ from the low-mountains $(83 \%)$ and 40 from the middle-mountains $(85 \%)$ were interviewed. Blood plasma analysis was performed in 64 women ( $63 \%$ of the total female population of the specified age period), 30 of them from the low-mountains and 34 from the middle-mountains. The chemiluminometric method for determining antioxidant (AOA) and antiradical activity (ARA) was used. Plasma AOA and ARA were determined by inhibiting luminoldependent chemiluminescence after adding the corresponding plasma samples. ${ }^{4}$ The procedure for conducting the experiment was in accordance with the standards of the Helsinki Declaration of 1983 (with further amendments).

Statistical data processing was performed using the software package "Statistica 6.0". If the data structure for the studied indicators were not described by the law of normal distribution, then further 
calculations were performed using nonparametric statistics using the Mann-Whitney U-test. If the actual distribution corresponded to the normal distribution, the reliability of differences in mean values was evaluated using the Student's t-test for independent variables. The reliability of differences in the distribution of women in groups depending on the age of menopause was assessed using the criterion- $\chi^{2}$.

\section{Results}

It was found that the body length in middle-mountains women was significantly lower (Figure 1), and BMI indicators were higher than in low-mountains women $(\mathrm{p}<0.001)$ (Figure 2). There was noted a tendency to earlier completion of cyclical menstrual function in high-altitude women in contrast to low-altitude women. Thus, in the middle-mountainsthe largest number of women with the first signs of menopause was aged 48 years, while in the low-mountains - 50 years (Table 1).

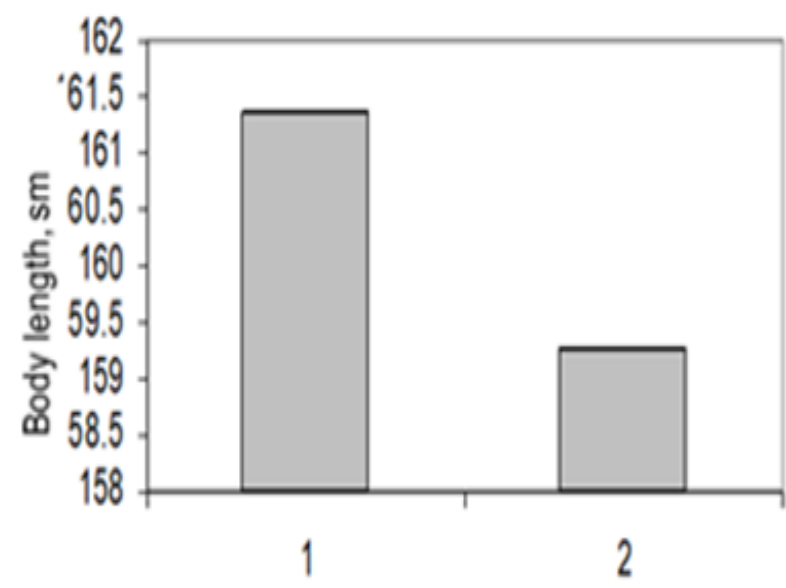

Place of residence

Figure I Significant differences by t-test between women's body length in low-altitude (I) and middle-altitude (2).

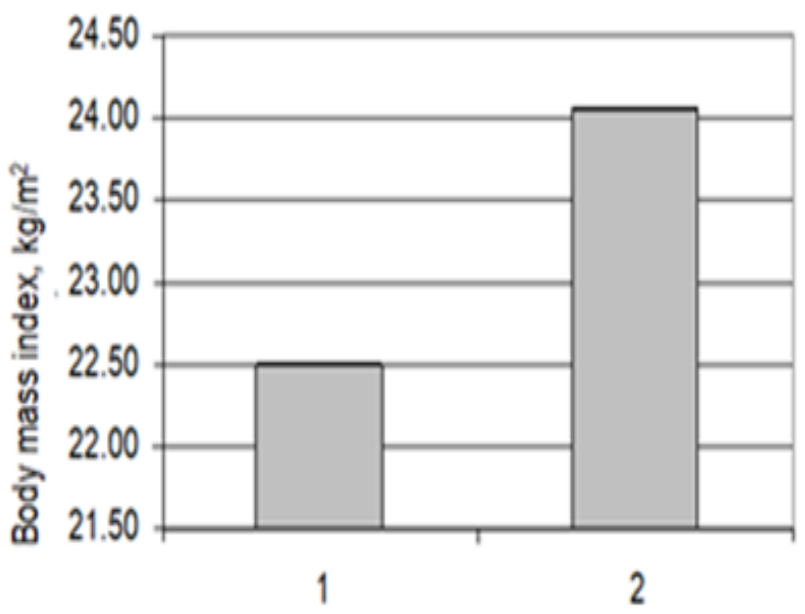

Place of residence

Figure 2 Significant differences by t-test between body mass index for lowmountains (I) and middle-mountains women (2).
Table I Distribution of women into groups depending on the age of menopause

\begin{tabular}{|c|c|c|c|c|}
\hline $\begin{array}{l}\text { Place of } \\
\text { residence }\end{array}$ & $\mathbf{n}$ & $40-45$ years & 46-5 I years & $52-56$ years \\
\hline middle-altitude & 40 & 11 & 28 & I \\
\hline low-altitude & 42 & 8 & 24 & 10 \\
\hline$\chi^{2}$ & \multicolumn{4}{|c|}{$\chi^{2}=8,87$, d.f. $=2, p=0,05$} \\
\hline
\end{tabular}

Analyzing the distribution of ARA values in the blood plasma of Altai women, we found that these parameters did not follow the law of normal distribution in all compared groups, so we evaluated the modal features. Firstly, it's necessary to make some remarks. The level of plasma antiradical and antioxidant activity was the higher, the lower the intensity of the sample glow after adding the studied plasma, i.e. the lower the photon $/ \mathrm{ml} / \mathrm{s}$ index, the higher the ability of the plasma to "extinguish" the glow of free radicals. Thus, the level of ARA in high-altitude women (modality 1067.6 (photons/ $\mathrm{ml} / \mathrm{s}$ ) was significantly lower than in low-altitude women (modality 129.8 (photons $/ \mathrm{ml}$ )/s) (Figure 3). The distribution of plasma AOA indicators showed an approximation to the normal distribution. The highest values of plasma AOA in the examined women were 205.9 (photons $/ \mathrm{ml}$ )/s in the highlands, and 71.6 (photons $/ \mathrm{ml}) / \mathrm{s}$ ) - in lowmountains. Consequently, higher luminance values (photons $/ \mathrm{ml}$ ) $/ \mathrm{s}$ ) of plasma samples from high-altitude women indicated a lower ability to suppress the activity of oxidants.

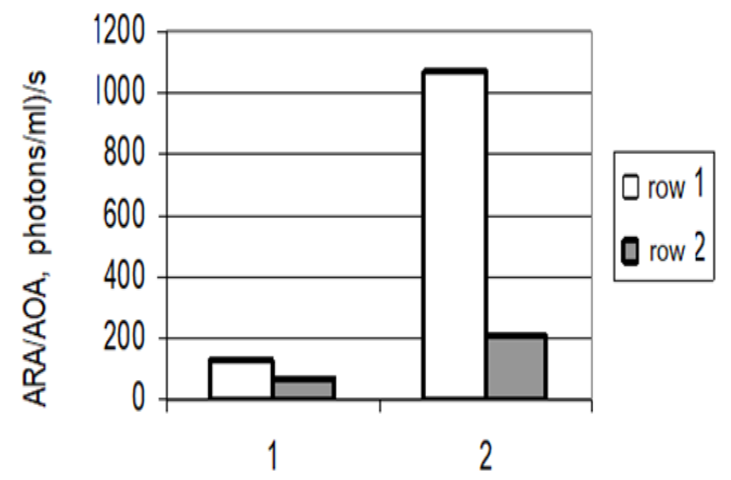

Place of residence

Figure 3 Modal signs of antiradical (row I) and antioxidant (row 2) plasma activity in women of low-mountains (I) and middle-mountains (2).

\section{Discussion}

It is known that a decrease in the relative surface of the body and a decrease in the relative length of the legs is an adaptive feature for living in a cold climate. This helps to reduce heat transfer and optimize thermoregulation mechanisms in low ambient temperatures. ${ }^{5}$ Questions about the dependence of the human's organism defense system on neuroendocrine regulation are widely discussed in the literature. ${ }^{6}$ Thus, the age-related changes in the hypothalamicpituitary-gonadal system cause a decrease in the plasma AOA. The dependence of the AO system of the human organism on the climatic factors of the environment was shown in extreme climate conditions. Apparently, the decrease in AOA and ARA in blood plasma of Altaic women in the southern Altai highlands was determined by unfavorable 
climatic conditions, on the one hand, and a shortened reproductive period, on the other.

\section{Conclusion}

Women in the population of southern Altaians of the highlands who live in conditions of climatic discomfort have adaptive signs, which are manifested in a decrease in body length, an increase in body mass index, a shortening of the reproductive period, and a decrease in blood plasma AOA and ARA.

\section{Acknowledgments}

None.

\section{Conflicts of interest}

The authors declare there are no conflicts of interest.

\section{Funding}

None.

\section{References}

1. Danilova IA. Interregional inequality in life expectancy in Russia and its age and cause of death components Social aspects of public health. Social Aspects of Population Health. 2017;57:3.
2. Berihanova RR, Minenko IA. The capabilities of complex non-drug programs in the correlation of psychoemotional climacteric disorders in patients with metabolic syndrome. Advances in Gerontology. 2019;32(12):159-165.

3. Ilovayskaya IA, Lazebnik LB, Kulikov AV. Central female hypogonadism as a model of premature aging. Advances in Gerontology. 2015;4(28):669673.

4. Krivova NA, Chanchaeva EA. Antioxidant activity of blood plasma of low-hill and middle-hill Southern Altai aborigines. Human physiology. 2011;2(37):178-183.

5. Sukhanova IV, Maksimov AL, Vdovenko SI. Age dynamics of morphofunctional alteration in young Europeans born in Magadan region. Gigiena i sanitariya. 2015;4:65-70.

6. Chanchaeva EA, Aizman RI, Gerasev AD. Contemporary perception of antioxidant system of human organism. Ehkologiya cheloveka. 2013;7:50-58.

7. Kolesnikova LI, Darenskaya MA, Rychkova LV, et al. Antioxidant Status in Adolescents of Small Siberian Ethnoses. J Evol Biochem Physiol. 2018:2(54):130-136. 